\title{
EL TEXTO, GENERADOR DE TEXTOS
}

El planteamiento central de este trabajo puede resumirse de la siguiente mancra: El creador de ciertas obras poéticas privilegia, entre otros, el uso de dos procedimientos lingüísticos para extender el tcxto más allá de su significación primera o "lectura inocentc"; uno se refiere al significado (uso de la homonimia, la polisemia y la connotación) y otro, a la estructura del mensaje (uso del simbolismo fónico y de la sintaxis combinatoria en varias direcciones). Con ellos, el pocta "cmpalma" varios significados en un solo significante y convierte la obra en una especic de crucigrama que el lector debe resolver.

Quiero advertir que el término generador que aparece en el título de esta investigación debe tomarse en cl sentido habitual del término ("que engeridra", "que origina") y no como un índice de incorporación de estas observaciones a la teoría poćtica que ha seguido el modelo propuesto por Noam Chomsky. ${ }^{\text {I }}$

\section{SOBRE EL LENGUAJE POÉTICO}

La compleja estructura del texto poético se ha presentado sicmpre como un reto a los especialistas en los diferentes campos del saber: sociólogos, psicólogos, antropólogos, filós sofos y lingüistas sólo son algunos de ellos. Esto resulta explicable si se tiene en cuenta que la obra literaria es un producto humano y que, por lo mismo, refleja diversos aspectos de la realidad; sin embargo, el interés por estudiar cada unode ellos con profundidad ha llevado a la especialización, a la

${ }^{1}$ Sobre esta corriente de la critica véanse: J. Roubaud, "Quelques theses sur la Poćtique", en Change, núm. 6; T. A. van Dijk, Some Aspects of Text Grammars, La Haya, Mouton, 1972, pp. 31-33; F. Lázaro Carreter, "La linguística norteamericana y los estudios litcrarios en la última década", en Revisto de Occidentc, 8 (1969), pp. 319-347. 
fragmentación unilateral en los estudios literarios. Se habla de crítica sociológica, sicológica, antropológica y otras más, pero se discute ampliamentc la insuficiencia de estos análisis parciales porque en cllos la "literariedad" de la obra pasa a segundo término. Ante cstos hechos, al tradicionalmente llamado crítico literario le quedan dos caminos: o bien sumar en su persona los distintos conocimientos especializados, o bien proponer un tipo de análisis especifico que ofrezca un punto de vista diferente, como podría ser, por ejemplo, el estudio de la función estética del texto. ${ }^{2}$

Poco a poco pirece que se va accptando una solución intermedia cntre la crítica parcial de la obra y la paráfrasis del texto; la scmiótica literaria vienc a unir ciertos aspectos de la crítica tradicional con las modernas técnicas descriptivas:

proponc o accpta nuevos principios, más o menos generales y claros, alcanzados unos mediante el análisis directo de textos, otros por vía discursiva, y pretende basar en ellos un método de análisis del texto de aplicación gencral. ${ }^{3}$

Aunque por el momento la crítica literaria semiológica todavía no ha logrado integrarsc plenamente, es indudable su importancia como instrumento de investigación. Sus antecedentes -formalismo ruso, semiótica filosófica y lingüística estructural-- la llevan a aceptar la obra literaria como una estructura (partes de un todo relacionadas entre sí) que debe ser analizada en sus componentes. 4 Éstos son lingüísticos y extralingüísticos; por tanto, su estudio debe seguir tambićn estas ctapas. El análisis lingüístico no agota el texto literario, 5 pero parece ser el punto más indicado para iniciarlo, porque impide la desviación prematura hacia las circunstancias exteriores que rodean al texto.

${ }^{2}$ Cf. I. M. Lotman, La structure du texte artistique, París, Gallimard, 1973; Jenaro Talcns y otros, Elementos para una semiótica del texto artistico, Matirid, Cátedra, 1978, pp. 30-36. p. 7.

${ }^{3}$ W. O. Hendricks, Semiologiat del discurso literario, Madrid, Cátedra, 1976,

4 Para un planteamiento lingüístico del método estructural véase: L. Hjelmslev, Prolegímenos a una teoría del lenguaje, Madrid, Gredos, 1977.

5 D. Alonso y C. Bousoño afirman: "La materia literaria no será nunca totalmente investigable por procedimientos cientificos" (Seis calas en la expresión lite- 
Actualmente se desca encontrar una ciencia de la literatura que no confunda-como ocurrió en ciertos momentos la paráfrasis del texto con su análisis, pues este último tiene que realizarse sobre la estructura misma de la obra, que cs de naturalaza lingüística. No se trata de expresar los cfectos que produce en mí la obra literaria, sino entender cómo está hecha y por qué razón se distingue de los textos no poéticos.

Roman Jakobson ha sido portavoz de una corriente interesada en cstudiar los elcmentos fundamentales del lenguaje poético. ${ }^{6}$ Amplía la teoría de las funciones lingüisticas propuesta por Karl Bühler e insiste en la necesidad de desmitificar "la poesía" y proceder a la postulación de hipótesis que ayuden a comprenderla racionalmente. 7 La función poética, ha dicho, es "la tendencia hacia el mensaje como tal" \& y debe cstudiarsc integrándola a los problemas gencrales del lenguaje. $^{9}$ Según él, la atención que pone el autor de textos poéticos en la selección y la combinación de elementos comunicativos es muy superior a la que usamos habitualmente, y por ello, los efectos que producen son tambićn diferentes;

raria cspañola, Madrid, Gredos, 1951, p. 10, nota 2); y N. Ruwet: "El estatuto de la linguiistica en relación con la poética y con los estudios literarios en gencral no puede ser más que el de una disciplina auxiliar cuyo papei es bastante análogo al de la fonćtica con relación a la lingüística misma" ("Limites de l'analyse linguistique en poétique", Langages, 12 (1968), p. 67); Cf. Tambićn, H. Lázaro Carreter, "Un soneto de Góngora", en Samuel R. Levin, Estructuras lingü ísticas en la punc" sia (presentación y apéndice de licrnando Látzaro Carreter), Madrice, Cátedra, 1977, p. 97.

${ }^{6}$ Cf. B. Trnka y otros, El Circulo de Praga, Barcelona, Aлagrama, 1971, especialmente, pp. 41-52.

7 "Los trabajos de ilustres investigadores en el aún titubcantc campo de la estilística, han hecho ya comprender al público que la obra literaria puede ser sometida a procedimientos de análisis muy poderosos y cjercidos sobrc zonas vita* les cic la estructura litcraria, sobre la que la crítica no podía decir nada, scncillamente porque, teniéndolas todos los días ante los ojos, era cicga para ellas" (D. Alonso y C. Bousoño, Stis calas. ., p. 10).

${ }^{8}$ Agunos autores, como lirédéric Irançois y otros, picnsan que se trata de un nivel de análisis de la comunicación, más que de una función. También discuten $y$ objetan, en parte, la función poética de Jukobson: G. Mounin, La communication pocitique, Paris, 1969; J. Culler, Structuralist Poctics, Londres, Routledge and Kegan Paul, 1975; F. Lâaro Carreter, "¿Es pośtica la función poćtica?", cn N. R. F. H., XXIV, nüm. 1(1975), pp. 1-12.

${ }^{9}$ R. Jakobson, "La lingüistica y la poética", en T. A. Scbcok, Estilo del lenguaje, Madrid, Cátedra, 1974, p. 135. 
pues a mayor complcjidad conceptual suele corresponder mayor complcjidad estructural.

Desde luego, habrá algunos textos cn que la misma sencillez y claridad de sus términos y construcciones sea un elemento estético, 10 pero cxisten otros que, desde su primera lectura, aparecen como estructuras complejas ya sea en el aspecto fonológico, en el semántico o en el sintáctico. Recućrdese el verso de Góngora, estudiado por Dámaso Alonso: "Infame lurba de nocturnas aves", en el que las cimas acentuales presentan una distribución no usual, debido a la simetría que guardan en el verso. 11

Es csperable quc las alteraciones a la norma lingüística que el poeta introduce en su obra sean portadores de nuevas imágenes; de ahí la necesidad de que el estudioso del texto poético esté dotado de los conocimientos lingüísticos necesarios para reconocer esas alteraciones, precisamente como alteraciones; ya que puede ocurrir que le parezcan sólo frases felices o ideas excelentes, pero que sea incapaz de verlas como signos de significados ocultos. 12

En el texto poético se pretende que todos los elementos signifiquen en alguna medida, que no haya unidades ociosas; en este sentido, ese texto se presenta al lector enterado y al analista como un crucigrama cn cl que aparecen cicrtas señales que deben seguirse para llegar a los significados escondidos tras la apariencia de la lectura primera. El poema es una suma de sentidos que se manifiestan gracias a la polisemia de ciertas palabras, a la riqucza combinatoria de las construcciones y al simbolismo fonético. Así, el poeta agranda y matiza el mensaje, aprovechando al máximo la capacidad comunicativa de los elementos que forman el signo lingüístico. Consi-

10 Recuérdese a este propósito algunos pocmas de A. Machado.

11 D. Alonso, "La simetría bilateral" en Estudios y ensayos gongorinos, Madrid, Gredos, 1970, p. 126.

12 "Por desgracia, la confusión del término estudios literarios con cl de crítica tienta al estudioso de la litcratura a remplazar la descripción de los valores intrínsccos de una obra literaria, por un veredicto subjetivo y ccnsor. La etiqueta crítico literario aplicada a un investigador de la literatura cs tan errónca como lo sería lia de crítico gramatical o léxico aplicada a un lingüista" ( $R$. Jakobson, "La lingïlística y...", en Estilo del longuaje, p. 128). 
deremos someramente algunos de los recursos emplcados en poesía para lograr este fin.

a) El significado. En este terreno son tres los procedimientos más empleados, a saber: la polisemia, la homonimia y la connotación. Con ellas se rompe la relación equilibrada entre significante y significado de los signos lingüísticos, porque con una palabra el autor puede referirse a varias realidades.

La polisemia -como se sabe- cs la propicdad que posee un significante de referirsc a varios significados que ticnen semas o rasgos semánticos comunes: casa de campo, casa de retiro, Casa de Austria. En cambio, entre los términos homónimos tal comunidad no existe: pata (de caballo), pata (hembra del pato), y por eso, al usarlos, el poeta prolonga su texto hacia diversos campos significativos a la vez.

Se ha observado que existe proporción directa entre cl carácter polisémico de una palabra y su frecuencia de aparición en el habla. ${ }^{13}$ Esto explica -en parte-la preferencia de los poetas por las palabras comunes, pucs con cllas se puede hacer referencia simultáneamente a dos o más realidades. De esta manera nacen los "tópicos" o palabras características de un autor o una época, 14 que se repiten con frecuencia, pero referidas a distintas realidades que tienen poco en común. Es difícil, en estos casos, descifrar el simbolismo de las palabras, pues hacerlo supone el conocimiento de la ideología que se sustenta en el texto, y para lograrlo es necesario investigar las situaciones externas que se relacionan con la obra: fuentes en que se inspiró el autor, textos de la época, concepción que ese autor tenía de la poesía y otras más.

En cuanto a la connotación, Andrć Martinet sc ha referido a ella diciendo que es:

${ }^{13}$ Cf. J. Dubois y otros, Diccionario de Lingü ística, Madrid, Alianza Editorial, 1979 , s. v. polisemia.

14 Los diccionarios nos dicen que tópico es "un lugar común", "un término manido", "gastado" o "usual". Estaś características se extienden también a construcciones linguísticas mayores. Véasc la siguicnte estrofa de Góngora: Cuando la rosada Aurora o violada, si es mejor (escojan los epíteros, que ambos de botica son). (Poesias, Mćxico, Porrúa, 1978, p. 52). 
todo aquello que un término o un elemento lingüístico es capaz de evocar, sugerir, cxcitar, implicar de manera neta o imprecisa. 15

Como puede verse, no se trata ya de variaciones del significado sino de su enriquecimiento. Es un fenómeno que permite decir cosas sin decirlas, y por esto resulta de gran utilidad en la construcción de los mensajes artísticos.

Es cicrto que cl valor de las connotaciones no siempre coincide entre los hablantes de una lengua, pero el poeta busca lograr esa coincidencia creando los contextos adecuados; utiliza la tendencia humana hacia la polaridad u oposición: belleza / fealdad, malicia / bondad, etc. y logra con ello crear "ambientes anímicos" en el lector para controlar su afectividad.

L.os lingüistas, en general, sc han mostrado muy cautelosos cn ese terreno, porque los matices connotativos se relacionan con los campos cxteriores que rodcan al texto; pero el estudioso de la literatura no podrá evitarlos porque casi siempre son elementos necesarios para lograr la comprensión total del mensaje. 16

b) Los sonidos. Muy cercano a la connotación está el simbolisno fonćtico. 17 Los recursos fónicos también comunican en cl texto poético. Sirven al autor para conseguir la "ambicntación" o "la música de fondo". El ritmo, la medida de los versos, la rima, la sclección de los foncmas que forman las palabras son muy importantes, porque todos ellos matizan el comunicado.

15 A. Martinct, "Connotations, poésic el culture", en ro henor Roman Jakobson, vol. II, La Haya, Mouton, 1976, pp. 1288-1294.

16 Cf. Josć Pascual Buxó, "listructuras lingüisticas y paradigmas idcológicas", un Acta Pótica l (1979), México, UNAM, pp. 3-22. Además, para el tratamiento histórico de la connotación véasc: Beatriz Garza Cuarón, La connotación: problew mas del significado, México, El Colegio de México, 1978. Entre otros, también sc han referido al problema de la connotación lingüistica: L. Bloomficid, L. Hjelms. lev, k. H. Bendix y U. Weinreich.

17 Ij simbolismo fónico ha sido estudiado descle la antigitedad hasta nuestros rlías. Cf. "Iil simbolismo lingüístico", en Vicente García de Dicgo, Lecciones de lingüistica española, Maclrid, Gredos, 1973, pp. 63-90; E. Alarcos Llorach, "Fonología expresiva y poesía", en Ensayos y estudios literarios, Madrid, Jucar, pp. 219 236; Pekman, La autonomía del significante. Además casi todos los manuales de Conctica se reficren a ćl con mayor o menor extensión. 
En la estrofa:

Tanto bailé con la moza del cura tanto bailé que me dio calentura

el ordenamiento acentual y la combinación de fonemas "pintan" acústicamente el ritmo del baile a que se refiere la estrofa. En el verso gongorino citado: "Infame turba de nocturnas aves" el contenido lóbrego del mensaje está reforzado por elementos sensoriales (tur-tur) que intensifican la atmósfera de obscuridad. En español, como en algunas otras lenguas, la calidad grave del fonema / $/ \mathrm{se}$ asocia a lo lúgubre, a lo misterioso. Por el contrario, los fonemas opuestos a éste: $/ \mathrm{i} / \mathrm{/} / \mathrm{a} /$, con frecuencia son utilizados en textos alegres.

Sin cmbargo, el simbolismo fonético sólo refuerza el significado de las palabras; no significa por sí mismo. Las reglas que lo rigen son muy parecidas a las que se dan en los sistemas musicales, $\mathbf{1 8}$ ya que tiene gran parecido con la música descriptiva, aunque su estructura sea muy rudimentaria.

c) Las construcciones. Ahora bien, si los clementos lingüísticos que interviencn en cl texto poético poseen características espccíficas en cuanto a la selección, la combinación de cilos también presenta cualidades propias. Al hecho de permitir la convivencia de dos sistemas en la cadena (sintaxis y versificación), con unidades propias (oración y verso), hay que agregar el paralclismo como fenómeno enriquecedor. Hopkins lo definió como "comparación en razón de la igualdad y comparación en razón de la desigualdad" cntre los clementos del texto. R. Jakobson, por su parte, afirma que es la "proyección del principio de equivalencia del eje de Ia selección sobre el eje de la combinación", 19 cn donde cada elcmento es punto de partida para una identidad o una oposición; lo que permite unir sonido y sentido en estructuras me-

18

"¿Por qué ocurre esto: que determinados fonemas se asocian con determinadas sensacioncs, con detcrminados sentimientos? No olvidemos que la expresión normal de la lengua se realiza, se manifiesta con sonidos. Todo sonido tiene un timbre detcrminado, pero se pueden agrupar en varias grandes porciones: sonidos agudos, sonidos graves, sonidos momentáncos, sonidos continuos" (E. Alarcos Ll., op. cit., p. 229).

19 R. Jakobson, op. cit., pp. 156 y 157. 
nores bimembres, que a su vez sc traban sólidamente para formar la cstructura total. Cada clemento ocupa un lugar preciso en cl comunicado; de ahí que el texto poético no permita ni la conmutación ni la permutación de sus elementos, porque el sentido se vería disminuido o perdido, si se alterara la distribución paralelística de sus componentes.

Pero hay tambićn otro factor que enriquece algunos textos poćticos y los prolonga: la distribución de los elementos en el sintagma y de los sintagmas en el poema. Ei juego que se da entre hemistiquios, versos y oraciones permite hacer diversas lecturas, ordenando estos elementos en dilerentes direcciones. Los sintagmas puede unirse no sólo con los que les anteceden y los que le siguen, sino también con otros que están alejados de ellos y que comparten algún rasgo formal, como el ritmo, la rima o el tipo de fonemas. Al unir esos elementos, se forman comunicados distintos - en mayor o menor medida-- del mensaje principal; se generan nuevos textos utilizando el mismo significante, sólo ordenándolo de diversas maneras. El autor cjercita así la capacidad lúdica deI artista: jucga con los significados de las palabras (polisemia, homonimia y connotación) y con el significante (soridos y construcciones), de lo que resulta el agrandamiento del texto en todos sentidos. Por eso, con frecuencia, cl texto literario dice más de lo que a primera vista aparenta.

Para cncontrar los sentidos subterráncos de este tipo de poemas, en ocasiones basta unir los versos en orden diferente al usual; pero en otros casos, la unión de versos necesita de cicrtos retoques sintácticos sccundarios, como omitir un rnismo elemento que se da en los dos versos y que es indispensable en su colocación original, o bien agregar algún nexo que está implícito en la significación de la palabra. Por eso, quizá cleba distinguirsc entre:

a) diversas lecturas de un texto (sólo se necesita leerlo en varias direcciones);

b) nuevos textos que se generan a partir del original (precisan de algunos retoques secundarios).

Las diversas lecturas se originan en el hecho de que la lengua escrita cuenta con un espacio físico en el cual se distribu- 
yen las letras y las palabras. Mientras la lengua oral desaparece inmediatamẹte después de pronunciada, la lengua escrita permanecc en su estructuración gráfica. En la primera, por su naturaleza instantánea, sólo existen mensajes lineales en una dirección; en cambio, en la segunda, el texto inmóvil permite organizar diversos mensajes siguiendo varias direcciones en la lectura. Esta posibilidad que está latente en todo escrito se cultiva intensamente en los pocmas crípticos.

La rima, el ritmo, la frecuencia en el uso de los fonemas y las relaciones sintácticas suelen ser algunas de las señales que los autores utilizan para lievar al lector hacia las lecturas múltiples; será necesario efectuar un análisis detallado de los mismos al estudiar los textos que posean esas características.

Por último, los elementos que forman el poema y la distribución quc guardan éstos en él no sc deben al azar; generalmente son fruto de laboriosa búsqueda por parte del poeta, aunque no necesariamente ćste sca consciente del análisis de esas estructuras. La creación poética es así una forma peculiar de seleccionar y combinar elementos, dentro de los límites impucstos por el sistema lingüístico.

\section{UN SONETO DE BERNARDO DI: BALBUENA}

Trataré de mostrar ahora, en un texto poético, dos de los procedimientos observados anteriormente, a saber: el "cmpalme" de significados en un solo significante y las lecturas múltiples.

En la obra Siglo de Oro on las selvas de Erifile, de Bernardo de Balbuena, aparece el siguiente soneto:

Mientras que por la limpia y tersa lrente

esc cabello de oro ensortijado

al fresco vicnto vuela marañado

sobre las ticrnas rosas del oriente;

mientras la primavera cstá presente

de esc clavel sobre marfil sentado, coged las flores y alegrías del prado, que el ticmpo corre, huye y no se siente. 
¿De qué fruto os scrá la hermosura, cuando el invicrno vista con su nicve la lumbre de oro y encarnadas rosas?

Si la cdad pasa, cl ticmpo la apresura, las horas vuclan, y en su curso breve hallan y tienen fin todas las costs. ${ }^{20}$

Lit primera lectura del soneto nos lleva a la conclusión de que cs uno de tantos que se hicicron en esá época sobre el tópico carpe dicm; ${ }^{21}$ sin embargo, el análisis atento del texto nos permite descubrir otro sentido oculto, al que se llega a través del estudio cstructural y de las "fuentes" en las que se inspiró Balbuena. ${ }^{2} 2$

a) Algunas palabras "claves"

En este apartado sólo me referiré a los versos 7 y 6 (en ese orden), porque considero que en ellos se cncuentra la clave principal del sentido segundo (religioso). Antes haré algunas obscrvaciones gencrales.

Sc distinguen dos sccciones en el soneto (versos 1 a $7 / 8$ a 14). Hay contraste cntre ellas en varios niveles: los temas (vida / muerte), las estrofas (cuartetos / tercetos), la sintaxis (oraciones amplias y en escaso número/oraciones numerosas y cortas) y la independencia sintáctica (cada sección tiene oración principal).

Diversos recursos privilegian las dos oraciones sintácticamente principales; la primera (verso 7) es la única que posee un imperativo; la scgunda (verso 9) es la única intcrogativa. Tienen cn común ser las únicas en las que predomina la función apelativa.

El mensaje central del texto aparece en los versos 7 y 8: el autor incita al lector a vivir la vida intensamente, porque el ticmpo de que se dispone para gozarla es muy breve. Sin em-

20 Possíl en lengua española. Siglos XVI y XVII, México, UNAM, 1971, p. 117.

21 Recuérdense por cjemplo los sonetos de Garcilaso y de Góngora: "Ein tanto que de rosa y azucena" y "Mientras por competir con tu cabcllo", respectivamentc.

22 Balbuena, al parecer, se inspiró paralclamente en fuentes poéticas profanas y religiosas; los tópicos que usa apareccn en los dos tipos de poesía. Se vale de los tópicos profanos para cnviar mensajes morales, como se habia hecho en el Mcster de Clerecia. 
bargo, al lcer el soneto saltan a la vista varias palabras que tienen diferentes significados simbólicos; las reconoccmos porque son tópicos que aparecen repetidamente, con más de un sentido, en las obras literarias anteriores o contemporáneas al autor: prado, flores, clavel, marfil, alegrias: todas ellas aparecen por igual en textos profanos y religiosos; de ahí la posibilidad de leerlos en los dos sentidos.

Las flores del prado (verso 7) de Balbuena, a la vez que son los placeres de la vida ${ }^{23}$ (Libro de Alexandre, Garcilaso y tantos otros), 24 también son las virtudes de la Madre de Dios (Gonzalo de Berceo): 25

Yo, maestro Gonzalo de Berceo nomnado, yendo en romería caecí en un prado verd o bien sencido, de flores bien poblado, lograr cobdiciaduero pora omne cansado. 26

Poco después el mismo autor explica el doble significado de sus versos:

Señores e amigos, lo que dicho habemos, palabra es oscura, exponerla quercmos; tolgamos la corteza, al meollo entremos, prendamos lo de dentro, lo de fucra dejemos.

23 "Todo lo que fluye y crece ha sido utilizado por las antiguas religiones como símbolo de la vida: el fucgo por su intensidad neccsitada de alimento, el agua por su poder fertilizante de la tierra, las plantas por su verdecer en primavera. Ahora bicn, todos o la inmensa mayoría de los símbolos de la vida lo son también de la muerte. Media vita in morte summus, decía cl monje medieval, y la ciencia moderna responde: La vie c'est la mort (Claude Bernard)" (J. E. Cirlot, Dicciona. rio de simbolos, Barcclona, Labor, 1978, s. v. vida).

24 En la descripción de la primavera que se presenta en El libro de Alexandre aparcce la siguiente cstrofa: "Andan mocas e vicjas cobiertas en amores, / van coger por la siesta a los prados las flores, / dizen unas a otras: $\rightarrow$ iBonos son los amores! / Fi aquellos plus tiernos tiéndesc por mejores"./ Garcilaso, por su partc, invita a gozar los placeres simbolizados por flores: "coged de vucstra alegre primavcra / el dulce fruto, antes que el tiempo airado / cubra de nieve la hermosa cumbre." (Soncto "En tanto que de rosa y azucena").

25 Gonzalo de Bercen, Milagros de Nuestra Señora. Principalmente en Ia "Introducción".

26 Las cstrofas de Berceo utilizadas en este trabajo pertenecen todas a la obra citada en la nota antcrior. 
Más adelante explica pacientemente cada una de las palabras que tienen sentido simbólico o metafórico. 27 Del prado dice:

En esta romeria habemos un buen prado, en qui trova repairc tot romeo consado, Ia Virgen Gloriosa, madre del buen criado, dal cual ninguno egual nin fuć trovado.

$Y$ de las flores explica:

Tornemos ennas flores que componen el prado, que lo facen fermoso, apuesto e temprado: las flores son los nomnes que li da el dictado a la Virgo María, madre del buen criado.

Bien se sabe que los nombres que los cristianos dan a la Virgen 28 se originan precisamente en las virtudes que le atribuyen. 29 El mismo Gonzalo de Berceo explica algunos de ellos en la obra citada.

Sin embargo, los dos autores (Balbuena y Berceo) no sólo coinciden en ciertas palabras, sino también en hemistiquios:

- Balbuena. Coged las Jlores y alegrías del prado

Bercco: Cuantos que son en mundo justos e pecadores, coronados e legos, reis c emperadores, allí corremos todos vasallos e señores, todos a la su sombra imos coger las flores.

Podemos concluir que las tres palabras claves del verso 7 de Balbuena, en sentido espiritual, tienen los siguientes significa. dos:

27 Llamo sentido simbólico o metafórico al tradicionalmente llamado sentido figurado; es decir los significados segundos que se dan por semejanza o analogía.

28 Gran número de cllos reunidos en la "Letanía a la Santísima Virgen".

29 Estos "nombres" son invocaciones; pueden ser simples: "Virgen Santísima", o compuestos: "Trono de la Eterna Sabiduría". En el primer caso se exalta una cualidad por medio del lenguaje en función representativa; en cambio en el scgundo, se usa lenguaje metafórico. 
coger: 'imitar', 'practicar', 'invocar';

flores: "virtudes' (nombres de la Virgen); 30

prado: "Virgen Gloriosa, madre del buen criado".

Esta complicada simbolización religiosa que se vale de los tópicos literarios profanos se encuentra repetidamente en los antiguos textos castellanos; el maridaje de sentidos humano-espiritual se da también en obras de carácter profano; aparentemente se está describiendo la naturaleza, pero los términos que se eligen son elementos simbólicos. ${ }^{31}$

Encontramos así, dos sentidos en los versos principales (7 y 8) del soneto de Balbuena; cllos son:

1) Goza los placeres de la vida porque tienes poco tiempo para hacerlo.

2) Practica las virtudes de la Virgen, porque el tiempo para hacerlo se agota rápidamente (y si no lo haces, no tendrás méritos para salyarte; versos 9,10 y 11 ).

Analicemos ahora el verso 6 en su dualidad humano/espiritual. Es un verso harto complejo tanto en su colocación sintáctica como en su simbolismo. Si estamos de acuerdo en que a-mayor complejidad estructural corresponde mayor

30 "Los empleos alegóricos de las flores son igualmente infinitos: atributos de la primavera, de Ia aurora, de la juventud, de la virtud" . . "San Juan de la Cruz hace de las flores la imagen de las virtudes del alma. El aroma que las asemeja es la perfección espiritual" (J. Chevalier, Dictionctire des Symboles, París, Seghers, 1974 , s. v. fleur\}.

Balbuena, con cierta frecuencia, se refiere al olor de las virtudes: "¿Quién me dirá desta real grandcza / cuál saic más, la gracia en su gobicrno / o el olor de virtud en su nobleza?"/ (Grandeza Méxicana, cap. VIII).

31. Si Gonzalo de Berceo, como hemos visto, compara a la Virgen con un prodo lleno de flores, por las virtudes que posee, en el Libro de Alexandre encontramos esta misma asociación semántica, sólo que la comparación se establece a través de otro "nombre" de María. Dice la estrofa que describe el prado: "lixié de la fontana una blanda flor, / de la sombra del árbol un temprano sabor;/.dava el arbolorio sombra e buena flor/semejava que era huerto del Criador"./

En este caso el prado "scmejava que era huerto del Criador". Debe recordarse que una de las advocaciones o "nombres" que cn la tradición cristiana se dan a la Virgen es precisamente "Hortus conclusus" (huerto cerrado), porque sóls Dios entró en ella (Madre de Dios). El libro de Alexandre no se ha considerado como obra religiosa y aun ahí aparecc este simbolismo doble. 
complejidad conceptual, podemos afirmar que en él está una parte fundamental del soneto.

Lo primero que puede observarse es su curiosa colocación dentro de la creación de que forma parte: es un complemento adnominal fuera de su lugar, pues muy rara vez la lengua española permite la separación de este complemento y su núcleo. Cualquier hablante reconoce como construcción anormal: La casa está cerrada de mi tío por La casa de mi lio cstá cerrada. Sin embargo, esta alteración sintáctica no es ociosa, pues precisamente ella es la que permite que cl verso 6 pucda scr a la vez micmbro de la oración subordinada temporal del cuartero y formar parte de la oración principal. Para csto último bastará lcer los versos en el siguiente orden: 5,7 , 6,8 . Haciéndolo así, la notable alteración sintáctica de la lectura original desaparcce y en su lugar se da una estructura perfectamente ordenada:

1) oración subordinada temporal (verso 5).

2) oración principal (versos 7 y 6 ).

3) oraciones subordinadas causales (verso 8).

En la nueva lectura, el verso 6 es complemento adnominal del objeto directo de la principal.

Ahora bien, el sentido denotativo de las palabras en el ordenamien to nuevo, resulta absurdo; no ocurre lo mismo cuando investigamos los significados simbólicos de las palabras claves: clavel, marfil, sentado.

Clavel tenía por lo menos tres significados en los siglos XVI y XVII:

1) 'flor roja'

2) 'Iabios de mujer' 32

3) 'Cristo'

32 "En dos labios dividido / Se ríe un clavel rosado, / Guarda-joyas de unas perlas / Que invidia el mar indiano" (L. de Góngora "Fábula de Leandro y Fero", cn Poesias, p. 68). 
Que este úlimo significado cra tópico de cse tiempo nos lo muestran los siguientes versos de Góngora:

Caído se le ha un clavel hoy' a la Aurora del seno; iqué glorioso que está el heno porque ha caído sobre él!

De un solo clavel ceñida la Virgen, aurora bella al mundo se le dio y ella quedó cual antes florida; a la púrpura caída sólo le fuc el heno fiel...

Sin duda que el clavel fue escogido como figura simbólica de Cristo principalmente por dos razoncs:

1) la tradición bíblica había simbolizado al Salvador del mundo por medio de una flor.

2) por el color rojo que frecuentemente tiene esta flor. El rojo es símbolo por excelencia de la sangre, del sufrimiento y del amor. ${ }^{33}$

La importancia del color rojo como símbolo de Cristo aparece con claridad al observar el otro nombre que Góngora utiliza para llamar a Cristo en el poema anterior: púrpura caida. El único sema que une las dos palabras es precisamente el intenso color rojo.

Pero hay otro simbolismo en la totalidad del verso que equivale también a 'Cristo': la unión de colores rojo y blanco. Tradicionalmente se han usado éstos como símbolos de la doble naturaleza divino-humana que se refleja en la inocencia y el sufrimiento (no culpabilc) de Cristo; de ahí las figuras que se han empleado para simbolizarlo: cl cordero blanco herido,

33 “Los colores de la reina / Visitó galán el clave, / Príncipe que es de la sangre, / u aun aspirante a ser rey" (L. de Góngora, "Romance del palacio de la primavera", en Poesias, p. 65); Cirlot, por su parte, afirma quc el rojo en la cultura humana ha sido asociado a "sangre, hcrida, agonía, sublimación" (p. 136). 
"cardenico alheli" lo llama también Góngora. 34 "Clavel sentado sobre marfil" está en esta serie. Tenemos así:

1) clavel: 'Cristo'

2) claval sobre marfil sentado: 'Cristo';

dos simbolizaciones que refuerzan cl sentido espiritual. Sin embargo, al tomar la primera posibilidad se plantea el problema del significado del resto del verso. ¿Qué sentido espiritual tiene: sentado sobre marfil?

Al consultar el Diccionario de la Real Academia Española encontramos tres accpciones de la palabra sentado: 35

1) participio pasivo de sentar

2) juicioso, sesudo, quieto

3) en botánica: aplícase a los hojas, flores y demás partes de la planta que carecen de pedúnculo.

Si tomamos los sentidos de clavel: 'flor' y 'labios femeninos' estaremos utilizando la tercera accpción:

1) 'un clavel cuyo pedúnculo está enterrado en un pedazo de marfil'

2) 'los labios rojos sobre la piel blanca semejan un clavel enterrado en un pedazo de marfil'.

En cambio, si se toma el tercer sentido: 'Cristo', entonces se . a la primera acención: participio pasivo de sentar; con lo que el so 6 quedaría de la siguiente manera:

"de esc clavel sobre marfil sentado: significa:

1.) 'de Cristo sentado sobre el trono', que a la vez significa

34 Ensalada: "En medio a la monarquía", en Obras poéticas, editadas por Fulche del Bosque, Nueva York, 1921, t. II, pp. 231-235. (Esta referencia se la debo a la Dra. Margit Frenk.) Balbuena utiliza también otras metáforas para unir cstos dos colores: "blanco aljofar en rubíes injerto", "has visto entre la nieve deshojada / una encarnada rosa / o algún rubi sobre marfil sentado / o a la nieve mezclada / la hojucla olorosa / del clavel rojo en carmesí bañado?", Siglo de
oro... Égloga 1.

35 Tomo sólo las acepciones que se relacionan con el texto estudiado. 
2) 'de Cristo quieto sobre la cruz' (segunda acepción de sentado).

Esta simbolización es bastante complicada por la lejanía que existe entre los elementos comparados, pero el camino que los une puede encontrarse claramente en textos anteriores o de la época.

La unión simbólica marfil-trono-cruz tiene un carácter plenamente religioso. El marfil, materia muy apreciada desde la antiguiedad, fue uno de los materiales de que estaba hecho el templo de Salomón (trono de Dios). Dice Góngora:
$\mathrm{Y}$ al de Salomón, aunque cran
Sus piedras rubios metales,
Marfil y cedro sus puertas,
Plata fina sus umbrales;
("Romance A la ciudad de Granada."). ${ }^{36}$

Pero también estaba hecho de marfil el trono de Salomón. Dice el Dictionaire des Symboles que el marfil, por su blancura es símbolo de la pureza y que su uso en el trono de Salomón lo puede asociar al simbolismo del poder, en el sentido de que su dureza lo vuelve irrompible e incorruptible. ${ }^{37}$

Para entender el segundo paso de la simbolización: tronocruz, hay que recurrir a los textos litúrgicos de la iglesia católica. La cruz en que murió Cristo fue el trono desde el que reinó, porque al redimir al hombre se convirtió en el rey de la humanidad:

Canta, oh lengua, la gloria de esta guerra, celebra el noble triunfo del madero di cómo un Redentor, Dios y Cordero sacrificado en tí ganó la guerra. ${ }^{3} \mathrm{~B}$

36 Puede verse en esta estrofa una nueva unión scmántica, y por esto sìmbólica, entre la madera (cedro) y el marfil.

37 Fl marfil, entonces, es símbolo de pureza y de poder; mismas características que se le atribuyen a la Cruz de Cristo, como podrá observarse más adelante.

38 Textos litúrgicos del Viernes Santo. 
Son múltiples los textos en que se atribuyen a la cruz las virtudes de Cristo: es santa, cs noble, es digna de adoración; pero existe uno en el que aparece claramente la asociación trono-cruz: "Pregonad entre las gentes que Dios reinó desde el madero." 39

Por lo demás, si analizamos los semas que componen los significados de marfil y de cruz de Cristo encontraremos que son muy parecidos, siempre y cuando aceptemos que en el significado mismo de esa cruz existen necesariamente elementos simbólicos, ya que esa es la razón de que no se confunda con otras cruces. Veamos:

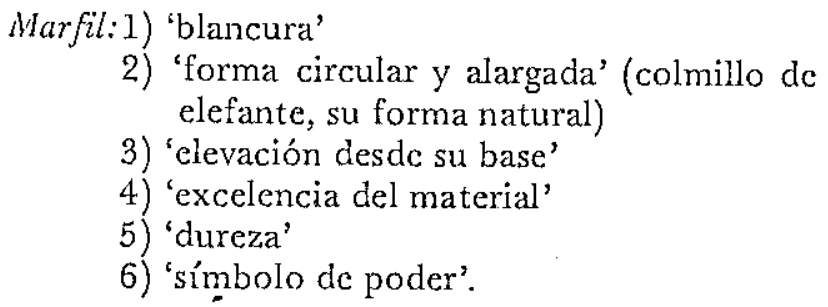

Cruz de Cristo: 1) 'blancura simbólica 40

2) 'forma circular y alargada'

3) 'elevación'

4) 'excelencia del material 41

39 Textos de la Misa Votiva de la Santa Cruz.

40 La blancura le viene a la cruz por su identificación con Cristo pues al ser instrumento de suplicio fuc el instrumento de la redención humana: "Oh bendixa Cru\%, que sola tú fuiste digna de llevar al Rey y Señor de los Cielos", canta la liturgia del Vicrnes Santo. Pero también la cruz es blanca porque cs santa, pues "la blancura simboliza el estado celeste" (Cirlot, s. v. blanco). Dice un texto de la Misa de la Santa Cruz: "Dios, que por la preciosa sangre de tu Unigénito Hijo quisiste santificar el estandarte de la vivificadora cruz, concédenos. .." Pero también la blancura de la cruz simboliza otra noción cristiana: para el cristianismo, antes de llegar a la santificación ( $y$ a la salvación) debe pasarse por el dolor (la cruz); éstc es el único camino. Así en el Apocalipsis de San Juan el blanco es el color del vestido de los que "han salido de la gran tribulación, han lavado su ropa y la han blanqueado con la sangre del Cordero" (Cirlot, s. v. blanco). Es decir, el sacrificio "blanquea". De ahi que cl simbolo (cruz) del sacrifiçio sca blanco.

41 "Oh cruz fiel, árbol único en nobleza / Jamás el bosque dio mejor tributo en hoja/ en flor y en fruto" (Liturgia del Vicrnes Santo). 
5) 'dureza' 42

6) 'símbolo de poder (espiritual).

Queda todavía una pregunta ¿por qué se han de practicar las virtudes de la Madre de Cristo crucificado (versos 7 y 6), es decir de la "Madre sufriente", según el sentido espiritual del soneto? Porque en él Balbuena nos está presentando la ideología católica: la vida es un lugar de prucba en donde se debe aceptar y gustar el dolor como paso necesario para llegar a la santificación y la salvación. Que éste es el sentido profundo del soneto se deduce de la limpidez estructural sintáctica con que es presentado. En cambio, la falsedad y la apariencia del mensaje que aparece en la primera lectura se ponen de manifiesto al observar la "artificiosidad" (la mala construcción) de la estructura; es una construcción falsa, por tanto: es un mensaje falso. Una construcción "no aceptada" lleva un mensaje "no aceptado". Si no fuera éste el sentido real del soneto, mal hubiera podido escribir Balbuena con su Compendio Apologético en Alabanza de la Poesía:

Al fin ha sido y es la pocsía, desde el principio del mundo, alegría y solaz suyo, tan agradable y dulce que con su deleite armónico concierta el ánima y le entretiene, compone el espíritu, mitiga la ira, alivia los trabajos, acompaña la soledad y, como dice Macrobio, despierta la virtud, recrea. . . ${ }^{43}$

El mensaje primero o aparente del soneto no "despierta la virtud", sino al goce de los placeres humanos. Esta doctrina pagana ha sido siempre condenada por la ideología católica y por la iglesia, de la que Balbuena era ministro; por tanto, hu biera caído en el ridículo cuando escribió:

42 El autor del himno litúrgico pide a la cruz que renuncie a su dureza: "Doble tus ramas arbol, lay! distiende / la fibra de tus entrañas, hazte blando; / de ti su madurez está colgando / la muerte sobre tí, muerto, la tiende" (Liturgia del Viernes Santo).

43 B. de Babuena, La grandeza mexicana y compendio apologético en alabanza de la poesía, México, Porrúa, 1975, p. 136. 
Y aunque yo conozco y sé esto y la (poesía) que aquí escribo no es del todo divina, es a lo menos honesta y grave. . "44

b) Las lecluras múltiples

Estas lecturas se distinguen de la original por la dirección que siguen, pero no debe pensarse que el lector o cl estudioso pueden inventarlas. La unión de los segmentos está determinada por la comunidad de ritmo o de rima y por la relación semántico-sintáctica. Aunque dos versos o hemistiquios tengan la misma rima, si no hay relación sintáctica entre ellos, no habrá tex to nuevo.

Los temas de las nucvas lecturas casi siempre son afines al tema principal y participan de la dualidad humano/espiritual que tiene el soneto; un texto podrá exaltar la belleza femenina y otro recordar el origen espiritual del hombre. En ellos aparece cmpleado el simbolismo con mucha frecuencia. 
Veamos algunos tipos de lecturas múltipıes:

1) Hemistiquios unidos por la rima:

versos

a) La hermosura $\quad 9$

el tiempo la apresura $\quad 12$

b) Imagen de la belleza femenina:

Oro ensortijado

sobre marfil sentado

c) Todas las cosas (son)

encarnadas rosas

2) Lectura alternada de hemistiquios y de derecha a izquierda

a) Todas las cosas

y (las) encarnadas rosas

14

hallan y tienen fin

11

(cn) la lumbre de oro

3) Unión de versos en dísticos

a) Ese cabello de oro ensortijado coged las flores y alcgrías del prado

b) ¿De qué fruto os será la hermosura Si la edad pasa (y) el tiempo la apresura

c) Mientras la primavera está presente (que) el tiempo corre, huye y no se siente 
d) Coged las flores y alegrías del prado 7 la lumbre de oro y encarnadas rosas ' 11

e) (que) el tiempo corre, huye y no se siente 8 sobre las tiernas rosas del oriente

4) Lecluras dentro de una misma clase de estrofas

a) Mientras que por la limpia y tersa frente (y) sobre las ticrnas rosas del oriente (mientras) la primavera está presente (que) el tiempo corre, huye y no se siente

b) ese cabello de oro ensortijado $\quad 2$ de esc clavel sobre marfil sentado $\quad 6$ (que) al fresco viento vuela marañado 3 coged las flores y alegrías del prado

5) Diversas lecturas de una misma estrofa

a) Mientras la primavera está presente coged las flores y alegrías del prado $\quad 7$ de ese clavel sobre marfil sentado $\quad 6$ que el tiempo corre, huye y no se siente. 8

b) Coged las flores y alegrías del prado 7 de ese clavel sobre marfil sentado 6 mientras la primavera está presente 5 que el tiempo corre, huye y no se siente. 8

c) ¿De qué fruto os será la hermosura 9 la lumbre de oro y encarnadas rosas $\quad 11$ cuando el invierno vista con su nieve? $\quad 10$

d) Cuando el invicrno vista con su nieve $\quad 10$ la lumbre de oro y encarnadas rosas $\quad 11$ ¿De qué fruto os será la hermosura? $\quad 9$ 
6) Existen estrofas que no aceptan lecturas múltiples 45

Si la edad pasa, el tiempo la apresura

\section{Antonio AlCALÁ Alba}

Centro de Lingüística Hispánica

Instituto de Investigaciones Filológicas

45 Sin embargo, sí aceptan la combinación con versos de otras estrofas para formar lecturas distintas. Sin duda la imposibilidad de combinarse los versos en otro orden se debe a que el mensaje que llevan en su lectura original vale tanto para la lectura con sentido humano o profano como para la que tiene sentido espiritual. 